\title{
El IMV: luces, sombras y futuro
}

\section{The IMV: lights, Shadows and Future}

Juan A. Gimeno*

Universidad Nacional de Educación a Distancia (UNED)

doi: https://doi.org/10.20318/labos.2020.5780

\section{Una medida necesaria}

El Ingreso Mínimo Vital que se ha implantado en España era una medida necesaria y urgente. Podemos agrupar las razones justificativas de tal afirmación en cinco puntos:

1. Porque lo exige la dignidad social

2. Porque los límites tolerables de la pobreza y la desigualdad se han sobrepasado

3. Porque el nuevo escenario económico y tecnológico lo hace imprescindible

4. Porque hay consenso social

5. Porque el sistema vigente de rentas mínimas es ineficaz

\section{Porque lo exige la dignidad social}

La Constitución señala como objetivo básico asegurar a todos una digna calidad de vida. Podemos discutir qué se entiende por "dignidad de vida". Imaginamos un cierto consenso en que debemos asegurar que nadie viva en la pobreza severa: en una sociedad como la nuestra, es intolerable (moral y socialmente) que haya hogares pasando hambre y sin sus necesidades básicas cubiertas.

Los Objetivos de Desarrollo Sostenible (ODS), fijados por Naciones Unidas con consenso universal, fijan la reducción de la pobreza como primer objetivo, y se concreta en metas como "reducir al menos a la mitad la proporción de hombres, mujeres y niños y niñas de todas las edades que viven en la pobreza en todas sus dimensiones con arreglo a las definiciones nacionales... poner en práctica a nivel nacional sistemas y medidas apropiadas de protección social para todos y lograr una amplia cobertura de los pobres y los más vulnerables" de forma que se garantice que "todos los hombres y mujeres, en particular los pobres y los más vulnerables, tengan los mismos derechos a los recursos económicos, así como acceso a los servicios básicos".

También el Pilar social europeo es muy claro en esa dirección: "Toda persona que carezca de recursos suficientes tiene derecho a unas prestaciones de renta mínima adecuadas que garanticen una vida digna a lo largo de todas las etapas de la vida, así como el acceso a bienes y servicios de capacitación".

Como señala la AIREF (2019, p.35), "la construcción de una última malla de seguridad económica para los ciudadanos que han agotado el derecho a otros recursos constituye uno de los rasgos distintivos de los Estados de bienestar europeos. En prácticamente todos los países de la Unión

*jgimeno@cee.uned.es

Este trabajo incorpora algunos textos de trabajos anteriores del autor. 
Europea existe una última prestación que trata de cubrir el riesgo general de insuficiencia o ausencia de ingresos, ya sea por la falta de acceso a otras prestaciones cuando se carece de un empleo o por haberse agotado el derecho a otros recursos. Aunque el diseño actual de estas prestaciones responde a motivaciones muy diversas, su objetivo básico es rebajar la incidencia de la pobreza a través del mantenimiento de un nivel suficiente de ingresos regulares."

Figura 1. Cuantías de algunas rentas mínimas en Europa.

\begin{tabular}{|l|c|}
\hline Alemania & 430 a $1.200 €$ \\
\hline Austria & Variable a $1.425 €$ \\
\hline Dinamarca & 476 a $2.035 €$ \\
\hline Finlandia & 400 a $1.250 €$ \\
\hline Francia & 550 a $1.050 €$ \\
\hline Grecia & 250 a $500 €$ \\
\hline Italia & 500 a $900 €$ \\
\hline Luxemburgo & 1.000 a $2.000 €$ \\
\hline Polonia & 200 a $557 €$ \\
\hline Reino Unido & a $1.176 €$ \\
\hline República Checa & 220 a $500 €$ \\
\hline
\end{tabular}

Una persona adulta a hogar de dos adultos y dos menores.

Fuente: Estimación propia a partir de diversas fuentes.

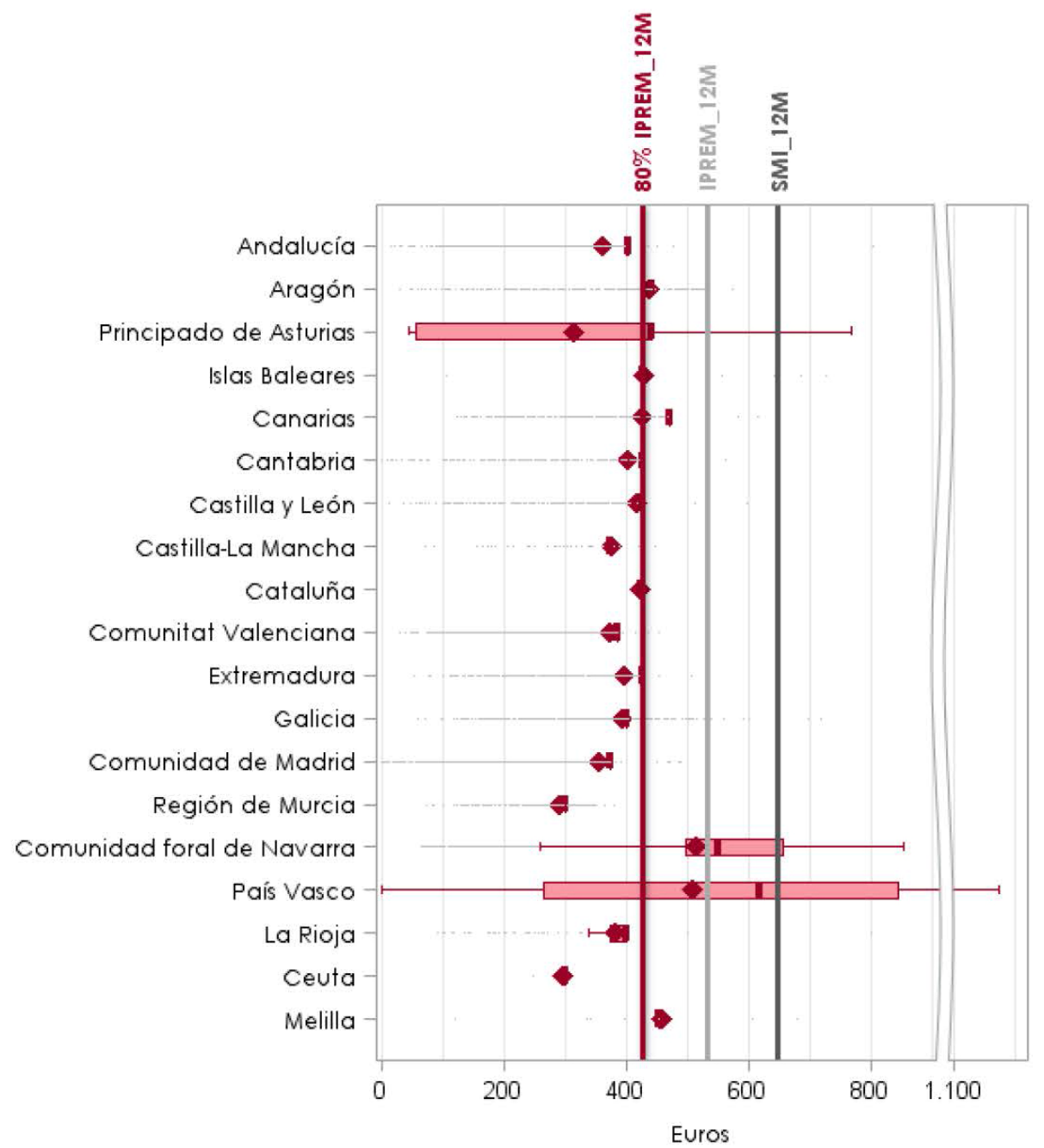

Figura 2. Cuantías mensuales (2015) observadas de los programas de ingresos mínimos de las ccaa en relación con IPREM y SMI. Fuente: Airef (2019), p. 16. 
Como vemos, el IMV no es ninguna medida novedosa o revolucionaria. Está generalizada en Europa. ¡Y está generalizada desde hace años en España! Todas las Comunidades Autónomas tenían programas de rentas mínimas con denominaciones y características muy diversas. Como veremos, el sistema es manifiestamente mejorable. Pero solo desde la crispación política y la actitud de oposición por sistema pueden entenderse las fuertes descalificaciones que acompañaron el anuncio de la intención gubernamental.

Europa y España entienden que una renta mínima garantizada es un derecho consolidado de ciudanía, inherente a la dignidad de las personas. Con muchas diferencias, eso sí, en cuantía, características y programas complementarios.

No puede asegurarse que la motivación sea la sensibilidad social, desgraciadamente ausente en tantas políticas española y europeas, de los últimos años. Es posible que muchos decisores políticos hayan actuado más por egoísmo que por solidaridad. Es sabido que la pobreza y la exclusión social provocan graves daños a la cohesión de una sociedad y menor crecimiento y que, tanto más cuanto más graves, son fuente potencial de desórdenes y de mayor delincuencia. Las élites pueden apoyar estas políticas como válvula de seguridad del sistema, para evitar que un exceso de descontento ponga en peligro el sistema mismo.

\section{Porque los limites tolerables de la pobreza y la desigualdad se han sobrepasado}

Según el Informe AROPE sobre el Estado de la pobreza en España (Llano Ortiz, 2018), en el año 2017, un total de 12.338 .187 personas, el 26,6 \% de la población residente en Espańa, estaba en Riesgo de Pobreza y/o Exclusión Social. Y el 5,1\% (más de 2,3 millones de personas) padecen pobreza severa, es decir, subsistía con menos de 342 euros al mes. Para la población menor de 16 años la tasa AROPE es del 31 \%: casi uno de cada tres menores está en riesgo de pobreza y/o exclusión social.

Dos años después, el mismo autor señala que el PIB per cápita en 2018 es de $25.727 €$, cifra que supone $1.598 €$ más que en 2008 , con un incremento porcentual del 6,6\%. A pesar de ello, la pobreza severa se mantiene todavía en el 9,2\% de la población, es decir, unas 800.000 personas más.

España estaba lejos de recuperar los datos previos a la crisis de 2008, y más aún de cumplir el objetivo de reducción de pobreza Europa 2020. Ostentamos posiciones de cabeza en cuanto al mayor crecimiento de desigualdad de la OCDE y en menor protección a las familias.

El 1\% de la población espańola concentra más riqueza que el $70 \%$ de las familias con menos recursos y trabajar ya no es garantía de abandonar la pobreza desde hace años.

El Informe del Relator Especial sobre la extrema pobreza y los derechos humanos en España (Naciones Unidas - 2020) es demoledor: "La economía española, cuarta de la Unión Europea, ha experimentado un crecimiento constante desde la crisis, propiciando una disminución del desempleo y un aumento de los salarios y las exportaciones. Sin embargo, la recuperación ha beneficiado principalmente al estrato más rico de la sociedad y, en gran medida, los poderes públicos han fallado a las personas que viven en la pobreza.

Como consecuencia de ello sigue habiendo situaciones de gran pobreza muy extendidas, una alta tasa de desempleo, una situación de desempleo juvenil crónico, una crisis de vivienda de enormes proporciones, programas de protección social muy insuficientes, un sistema educativo segregado y cada vez más anacrónico, políticas tributarias y de gasto que favorecen mucho más a las clases acomodadas que a las pobres, y una mentalidad burocrática que permite a las autoridades eludir su responsabilidad y valora más el formalismo que el bienestar de las personas. Resulta más que evidente que el sistema de prestación de asistencia social está roto, no se financia adecuadamente, es imposible no perderse en él y no llega a las personas que más lo necesitan”. 
El COVID-19, y las restricciones que ha conllevado, han venido a agravar súbitamente la situación. Oxfam - Intermon (2020) estima que esta crisis provocará que el decil más pobre de la población pierda más de ocho veces la renta que pierde el decil con mayores ingresos y un aumento de la desigualdad de la renta. Teniendo en cuenta las estimaciones de caída del PIB y el aumento del desempleo, el número de personas pobres en Espańa puede aumentar en más de 700.000 personas, con casi dos puntos de incremento del porcentaje de población en riesgo de pobreza o exclusión social.

Con estos datos, era necesaria y urgente una medida que intentara paliar esa situación de miles de hogares en gravísima necesidad.

\section{Porque el nuevo escenario económico y tecnológico lo hace imprescindible}

Este panorama de pobreza y desempleo tiene visos de prolongarse en el tiempo. No estaríamos ante una crisis coyuntural de la que vaya a salirse fácilmente. Aunque superemos la pandemia y ello permita una cierta recuperación de la actividad económica, hay factores estructurales que vienen avisando de una etapa del mercado de trabajo muy complicada, con niveles crecientes de desempleo y dualidad consolidada.

Los cambios tecnológicos están provocando la sustitución creciente de mano de obra por máquinas inteligentes en todos los sectores. Esta revolución parece llamada a provocar el crecimiento del desempleo, de las desigualdades y la pobreza, dificultades para mantener la demanda global, ralentización del crecimiento...

Es cierto que este pesimismo acompañó los inicios de anteriores revoluciones económicas y que, en todos los casos, a medio plazo se produjo el necesario reajuste para recuperar la senda del empleo y el crecimiento. Pero ahora tenemos varios factores que pueden suponer resultados diferentes.

Por un lado, en los ejemplos históricos se destruían empleos de baja cualificación, pero se creaban otros nuevos donde esas personas desplazadas encontraban fácil acomodo. Lo que caracteriza a esta revolución tecnológica es que los nuevos empleos son extremadamente divergentes:

- o requieren capacitaciones radicalmente diferentes de las que vienen a sustituir, por lo que no cabe el trasvase a la "nueva economía" de los expulsados de la "vieja economía".

- o se crean múltiples empleos de ínfima cualificación, las más de las veces acompañados de contrataciones precarias, cuando no fraudulentas, con grave deterioro de derechos y garantías laborales.

Se consolidan así tendencias que ya venían apareciendo en los últimos años como la dualización del mercado de trabajo y la precarización creciente de gran número de empleos. Cada vez es más frecuente la circunstancia de que tener empleo no garantice salir de situaciones de pobreza y exclusión social. La Comisión Europea (2019) subraya que los cambios que la economía digital están provocando en los mercados de trabajo obligan a desligar las políticas tradicionales de subsidios del viejo concepto de empleo estable.

Por otro lado, no podemos ignorar que estamos en una situación de emergencia climática que está obligando a revisar muchos de los fundamentos en los que se basaba el crecimiento. La inevitable transición energética es probable que implique también cambios estructurales que lleven aparejados ajustes en el empleo, tanto cualitativos como cualitativos.

En todo caso, el pleno empleo tal como lo conocimos es muy posible que tarde décadas en volver y lo hará en formas diferentes. Es previsible que a largo plazo los mercados se reajusten y puedan recuperarse niveles de empleo y condiciones de trabajo aceptables. Pero ese largo plazo puede 
ser muy largo y quienes sufran la exclusión durante ese tiempo necesitan una respuesta rápida. Ya se sabe, como decía Keynes, que a largo plazo, todos muertos.

\section{Porque hay consenso social}

Ante las situaciones de necesidad, las sociedades más avanzadas han ido consolidado paulatinamente un sistema general de garantía de rentas. Así, se iniciaron los sistemas de pensiones y el subsidio de desempleo. Se piensa en las personas que pierden sus ingresos por dejar de trabajar y se arbitra un sostenimiento de sus rentas.

Después, se observa que, a pesar de esos sistemas, hay personas que pasan necesidad porque no tienen acceso a ellos por no haber cotizado lo suficiente, o que reciben prestaciones ínfimas, o agotan los periodos para los que tienen derecho a prestación... Y se incorporan diversas prestaciones asistenciales para quienes quedaron fuera o para cubrir mínimos o prolongar prestaciones de forma extraordinaria.

También se van aprobando programas para colectivos concretos (viudedad, orfandad, discapacidad ...) que se consideran no cubiertos por los programas anteriores... Toda esa larga lista de medidas, sin embargo, siguen dejando fuera a muchos hogares que continúan en situaciones de pobreza y exclusión social, Surgen así las mencionadas rentas mínimas autonómicas - de diversos nombres, cuantía y eficacia - como última garantía de ingresos.

De alguna forma, tenemos un conjunto de políticas que pretende garantizar a todos los hogares una renta mínima garantizada, con los problemas que ahora veremos. En cualquier caso, esa evolución demuestra que, en sociedades como la nuestra, se considera normal buscar soluciones para quienes tiene problemas de supervivencia.

Ese consenso social se refleja asimismo en las encuestas disponibles. La figura 4 muestra que, de media europea, más de la mitad de la población es favorable a una renta básica. Y el porcentaje crece hasta acercarse al $70 \%$ en favor de una renta mínima condicionada a bajos ingresos. En España, los resultados son más diferenciados: casi un ¡ $90 \%$ ! apoya la renta mínima, aunque queda levemente por debajo del 50\% la posición favorable a la renta básica.

Es obvio que hay que tomarse con cautela estos resultados. Por un lado, porque la experiencia muestra que el apoyo se reduce cuando se coloca al lado el coste fiscal que podría acarrear la figura. Por otro lado, porque es generalizada la confusión terminológica y no todo el mundo diferencia entre rentas mínimas y renta básica de forma adecuada. Obsérvese (figura 5) que, en España, más de la mitad de los favorables a la renta básica se muestran partidarios de que se circunscriba a las rentas más bajas en tanto por ciento superior incluso al observado para la población total. No obstante, esta aparente contradicción puede no serlo tanto.

Curiosamente, no llega al 50\% (ni en España ni en la media europea) el porcentaje que apoya que las prestaciones económicas sean solo para las personas con rentas más bajas. Podemos concluir, razonablemente, que parece existir un consenso elevado en favor de un sistema que garantice ingresos mínimos a la población que lo necesite. Pero que ese consenso ya no es tan claro cuando hablamos de implantar una renta básica.

Más concreto y próximo en el tiempo es el sondeo realizado en la primavera de 2020 por el CIS, referido expresamente a la posible implantación del IMV anunciada por el Gobierno a raíz de la crisis del coronavirus: a favor $83,4 \%$; en contra $12,4 \%$. Tan aplastante mayoría favorable explica posiblemente que finalmente el Pleno del Congreso apoyara con 297 votos a favor, 52 abstenciones y ningún voto en contra la convalidación del Real Decreto-Ley que regula esa renta mínima. 


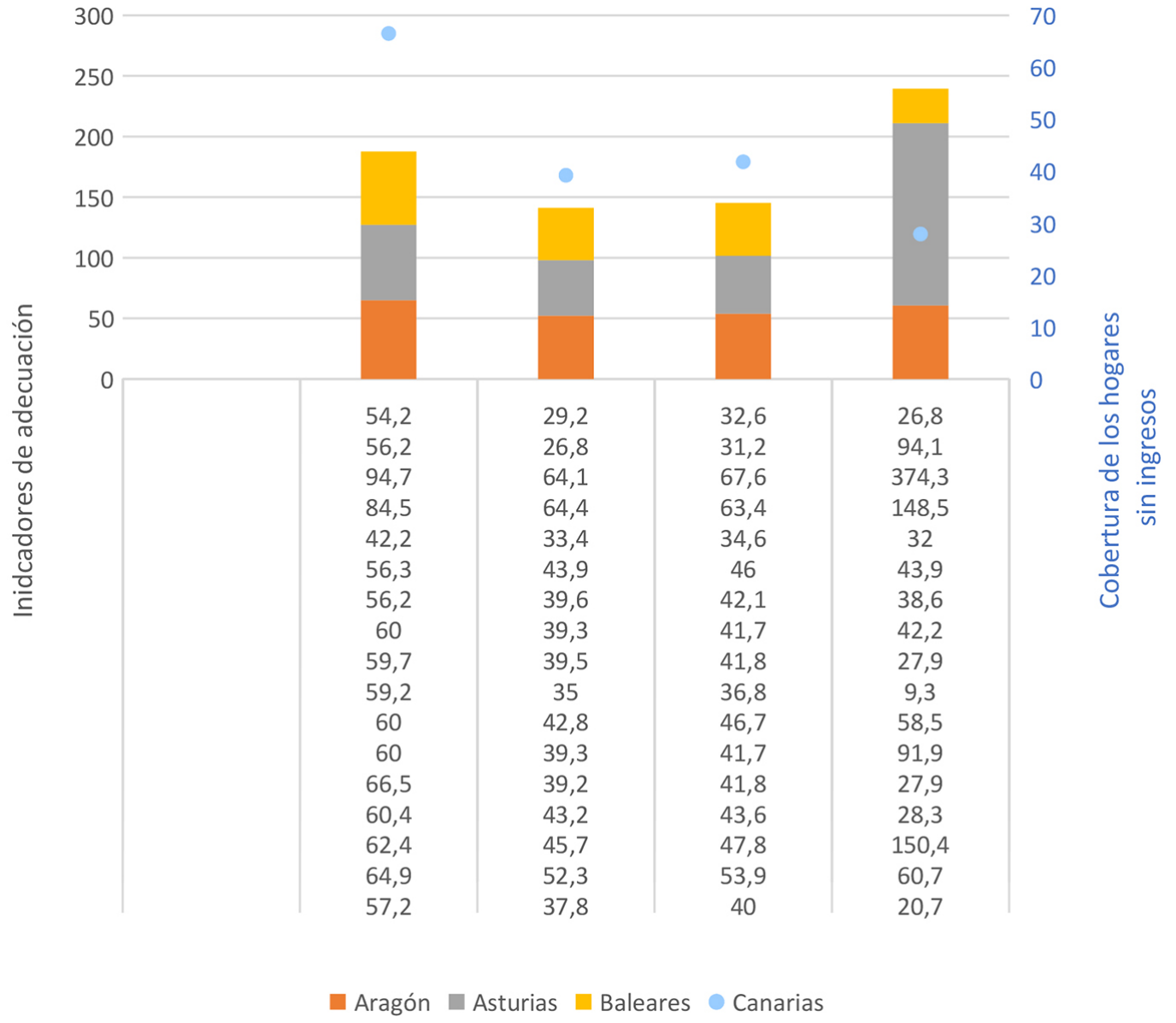

Figura 3. Adecuación y cobertura de los programas de ingresos mínimos de las CCAA.

Fuente: Elaboración propia a partir de AIREF (2019).

\section{Porque el sistema vigente de rentas minimas es ineficaz}

Se supone que el objetivo principal de las rentas mínimas es el de eliminar o reducir la pobreza. Sin embargo, los estudios académicos sobre la efectividad de estos programas (Bollain y Raventós, 2019), muestran el escaso cumplimiento de dicho objetivo,

Tenemos un sistema deslavazado y complejo que, además, no cumple con su misión redistributiva. España se mantiene año tras año como uno de los países con mayor desigualdad en la distribución personal de la renta, sólo superada por Bulgaria, Lituania y Letonia, países con menor nivel de renta y Estados de Bienestar menos desarrollados.

Esta posición se mantiene en el tiempo, lo que invita a pensar en factores estructurales. Uno de ellos, sin duda, es tanto el menor esfuerzo en gasto social como la menor capacidad que tiene éste para reducir la desigualdad. En el caso de las prestaciones monetarias (Figura 6), la capacidad del sistema para reducir la desigualdad de las rentas primarias es muy inferior a la de otros países, incluso varios con una renta per cápita sensiblemente inferior a la española. De nuevo, Espańa se incluye en un grupo de países con los que tiene muy poca afinidad económica, geográfica e institucional. Una parte muy importante, además, de este efecto se debe a las pensiones, siendo mucho más limitado el efecto de otras prestaciones monetarias. Como ahora veremos, los programas de rentas mínimas son especialmente deficientes. 


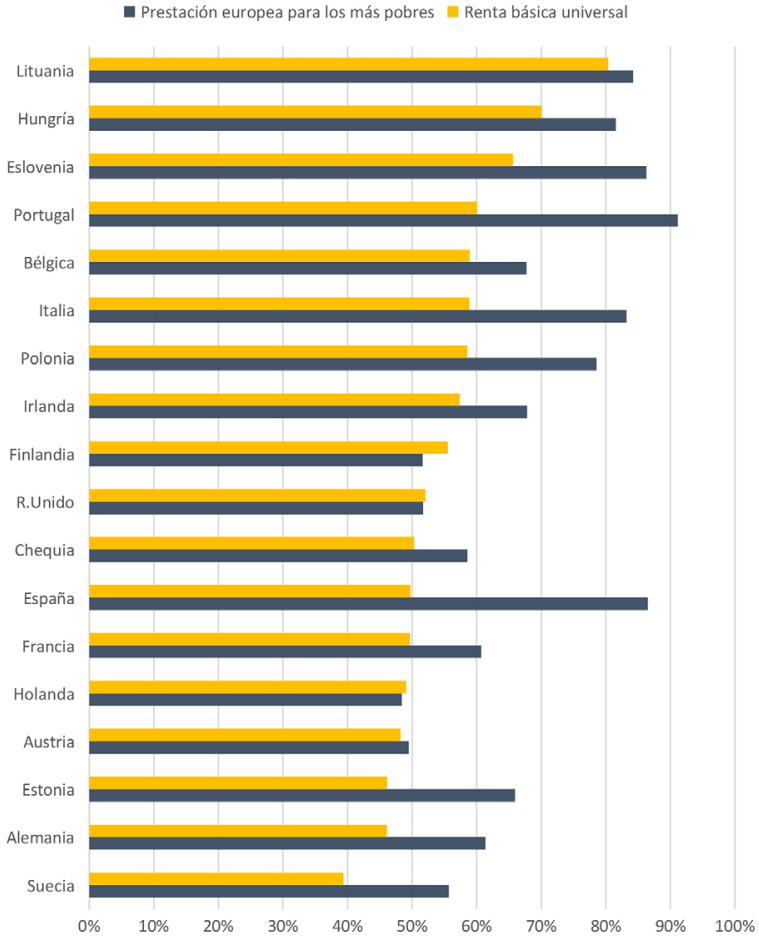

Figura 4. Porcentaje de población en favor de cada opción.

Fuente: European Social Survey (2016).

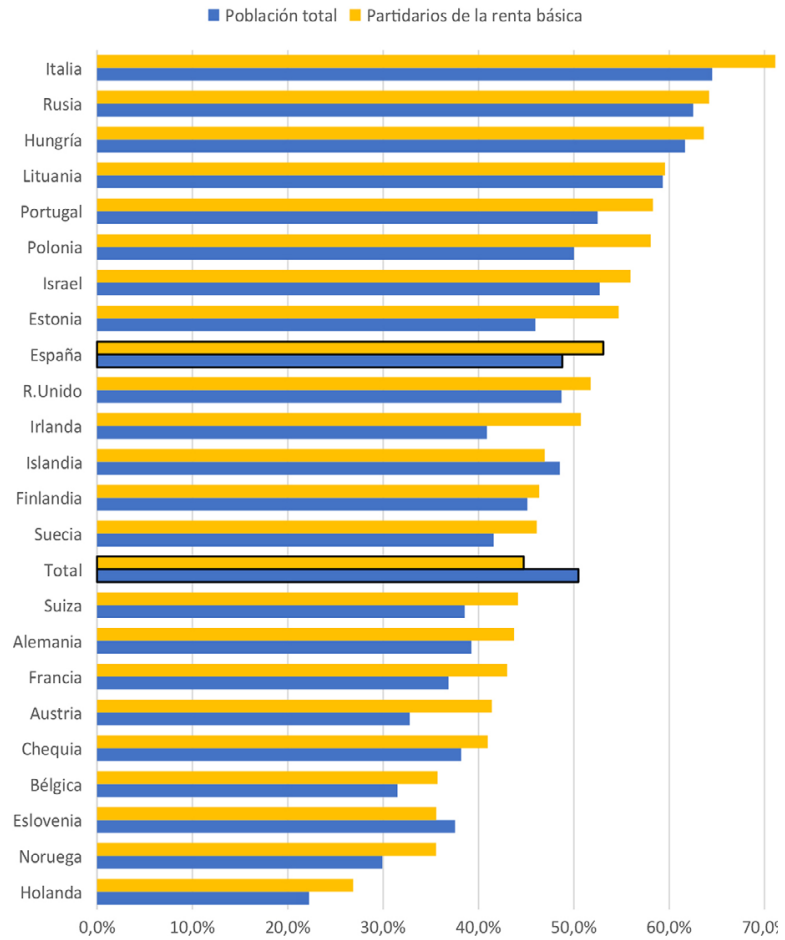

Figura 5. Porcentaje de población que apoya que las prestaciones económicas sean solo para las personas con rentas más bajas.

Fuente: European Social Survey (2016).

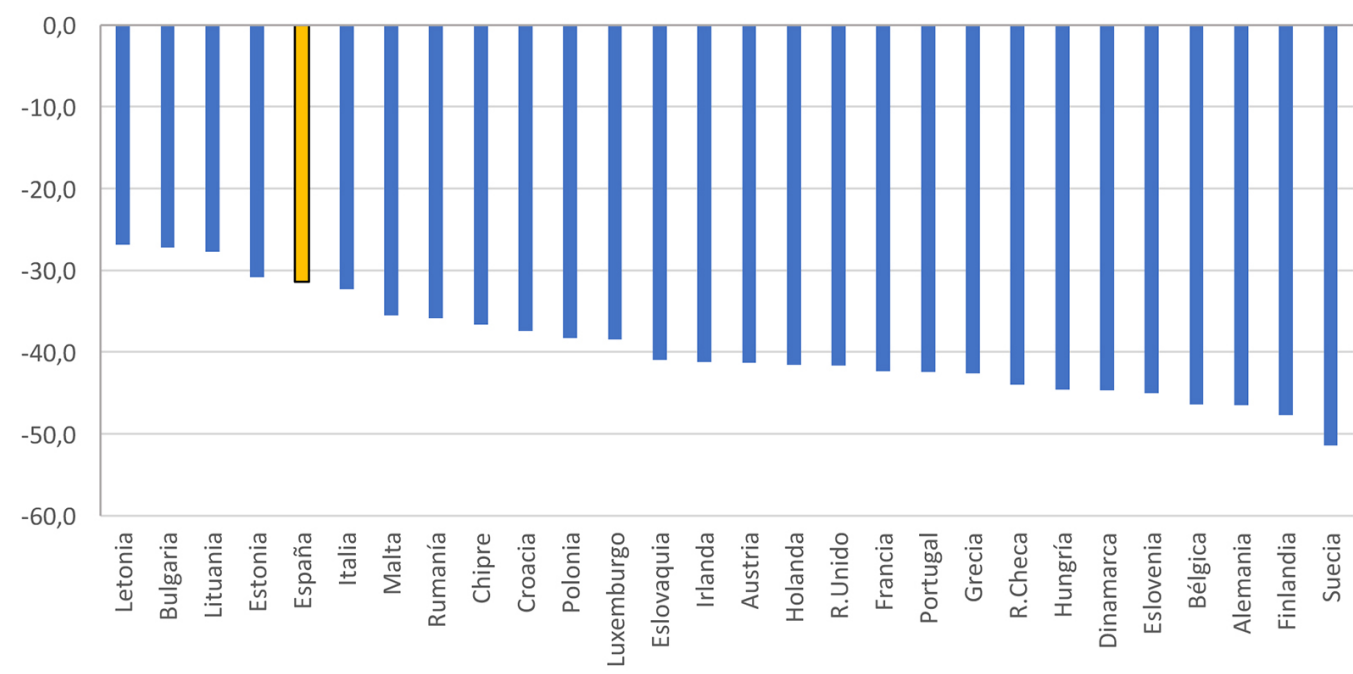

Figura 6. Reducción del índice de Gini por las prestaciones monetarias.

Fuente: EU-SILC (Eurostat).

Por todas las razones que hemos repasado, parece incontestable la necesidad y conveniencia de incorporar a nuestro ordenamiento el IMV, que ha de calificarse como un avance positivo. Se reconoce la prestación como derecho subjetivo incorporado al catálogo de prestaciones no contributivas de la Seguridad Social. Se ha consolidado la renta mínima como un derecho, desarbolando a los grupos opuestos y a los políticos timoratos, que tuvieron que rendirse ante la presión social favorable.

Lo que no impide reconocer que este IMV presenta sombras evidentes. Aunque la mayor parte de ellas sean comunes a todas las políticas de rentas mínimas condicionadas. 


\section{Muchas sombras}

El primer problema es que el IMV (en general, todo el sistema de rentas mínimas) deja fuera a demasiadas personas. Como hemos visto, la parte esencial del sistema de garantía de ingresos mínimos sigue presuponiendo que el pleno empleo es lo normal y que solo hace falta buscar solución para jubilados y desempleados. De entrada, esa presunción perjudica a las mujeres - tradicionalmente excluidas en mayor medida del mercado laboral -, a los niños - en un país como España que se sitúa a la cola en ayudas familiares - y a los jóvenes que no consiguen acceder al mercado de trabajo.

Quedan fuera de protección, también, los eternos invisibles, tan excluidos que ni están en las encuestas, ni tienen cuentas, ni, por supuesto, internet. Y muchas situaciones que no cumplen las complejas condiciones fijadas para tener derecho a la prestación, pero están en situación de necesidad. Se han señalado, a modo de ejemplo, hogares que el año anterior llegaban al mínimo, pero que en el contexto de la COVID-19 han generado ingresos bajos o nulos. O los casos de las unidades familiares que tienen un ingreso aparentemente suficiente en términos nominales (y superior a los máximos fijados), pero que poseen un volumen elevado de deudas originadas por el desempleo o la caída de ingresos

Quedarán fuera también todas las personas con ingresos superiores a los marcados como requisito para generar el derecho: los ingresos mensuales máximos deben ser menores a 462 euros en el caso de una persona adulta que viva sola y se incrementan otros 139 euros más al mes por cada persona adicional, adulta o menor, que conviva en la unidad de convivencia hasta un máximo de 1.015 euros al mes.

Puede parecer obvio que hay que fijar alguna frontera, especialmente si queremos que llegue a los realmente necesitados. Pero no es tanto que se caiga una vez más en el error de salto habitual en estas prestaciones. Si ganas 463 euros y vives solo te quedas fuera. Y una pareja con tres hijos y una renta de 1.016 euros al mes, también queda fuera. Cualquier sistema justo de prestaciones ha de montarse de forma decreciente, o provocarás resultados absurdos como los descritos.

Dejar fuera a las personas que superan por poco los mínimos que permiten acceder a los subsidios pero que están sufriendo las sucesivas crisis es grave. Se margina a una clase media baja (y no tan baja), que está pasando graves apuros económicos (especialmente en esta situación pandémica) y que tiene la justificada sensación de soportar la mayor parte de la recaudación tributaria, en un sistema fiscal injusto que recae desproporcionadamente sobre el trabajo asalariado. Se está abonando así la desafección de amplias capas de la población respecto al estado de bienestar, la solidaridad social y el propio sistema democrático. ${ }^{1}$

Desde el feminismo siempre se ha criticado el frecuente agrupamiento por hogares de las prestaciones monetarias. También el IMV toma los hogares como unidad de referencia. Es cierto que el cálculo por hogares aporta una mejor aproximación a las necesidades reales. Tanto porque la presencia de menores a cargo o personas dependientes incrementa las necesidades, como porque existen economías de escala. No obstante, es importante que la asignación se reparta de forma individual entre "cabezas de familia". Sin perjuicio de facilitar la vida independiente de las personas con discapacidad y la emancipación de los jóvenes. Se respeta de esta forma la igualdad, frente al tradicional monopolio del varón en la pareja convencional y otras concepciones paternalistas.

Una pregunta que nos hacíamos ante la introducción el IMV era cómo se armonizaría con los programas de garantía de rentas de las comunidades autónomas. Creo que el artículo 41 de la

${ }^{1}$ Es cierto (MARTÍN CARRETERO - 2019) que otras prestaciones, como las pensiones, operan en sentido opuesto - favorecen más a las clases medias que a los más necesitados - pero no sucede así con las rentas mínimas ni otras prestaciones asistenciales. En cualquier caso, no evitan el problema del error de salto ni la percepción subjetiva dominante como la descrita. 
Constitución habilita un ingreso mínimo vital a cargo de la Seguridad Social, que garantice un suelo igual para cualquier persona. Pero es imprescindible que se coordine el sistema con las CCAA, para evitar duplicidades y despilfarros, para ganar eficiencia, para garantizar una efectiva igualdad en contextos con costes de la vida diferentes y la atención a colectivos y necesidades especiales. Ese acuerdo es especialmente relevante en el caso de las Comunidades Forales, País vasco y Navarra, donde más y mejor se han desarrollado los sistemas de rentas mínimas. De hecho, fue de ellas de donde surgió la presión para coordinar la gestión y, hasta el momento, las únicas que habían firmado un protocolo de gestión conjunta. Evidentemente, la urgencia y rapidez de la media puede servir como atenuante, pero la celeridad con que se aceptó esa entrada en la gestión muestra que, probablemente, habría sido fácil alcanzar un acuerdo previo. También los Ayuntamientos están llamados a complementar, además, el acompańamiento hacia el empleo que corresponda. Desgraciadamente, en los primeros meses de aplicación, son muy pocos los que han firmado acuerdos en tal sentido.

Como era previsible, el IMV ha encontrado un obstáculo decisivo: la burocracia. Son de sobra conocidos los problemas que está arrastrando la aplicación del IMV, hasta el punto de que lo que era una medida de éxito ya es para algunos un fracaso. Y en parte lo es cuando las personas necesitadas no lo están recibiendo, muchos están quedando fuera de antemano por no poder superar esa barrera y la mayoría de los beneficiarios finales recibirá el subsidio con notable retraso.

Desgraciadamente, ese problema es prácticamente inherente a los programas de rentas condicionadas. El hecho de exigir el cumplimiento de una serie de requisitos implica la necesidad de una solicitud previa, de un acopio de papeles, de un esfuerzo de comprensión... que son barreras infranqueables para muchas personas. En la práctica, quedan fuera de este tipo de prestaciones la mayoría de los potenciales beneficiarios. Es desolador que, en 4 meses, solo el 1\% de los potenciales destinatarios se ha beneficiado del programa.

Las trabas burocráticas aparecen, efectivamente, como la principal razón explicativa de que en todas las prestaciones destinadas a personas en situación de riesgo de pobreza o exclusión queden fuera porcentajes elevadísimos (en algunas estimaciones podría superar hasta el 90\%) de los potenciales beneficiarios

$\mathrm{Al}$ mismo tiempo, comprobar esos requisitos exige un fuerte aparato burocrático, unos costes desproporcionados respecto al propio presupuesto del programa y un grave retraso en la percepción efectiva de la prestación, como estamos comprobando. Un entramado que, además, se sustenta en la profunda desconfianza respecto a los más necesitados. Se gastan probablemente más recursos en perseguir posibles abusos que el gasto que estos pueden suponer. Condenamos a los servicios sociales a dedicar más tiempo a tareas de control que a la atención a las necesidades reales de los colectivos necesitados.

\section{Una solución más eficiente}

El resultado: los sistemas de rentas mínimas condicionadas son ineficaces e ineficientes. No llegan a quienes debería llegar, no corrigen la pobreza ni la desigualdad, cuestan muchos recursos burocráticos y son extremadamente complejos. El IMV, como condicionado que es, aunque introduce algunos avances positivos respecto a las prestaciones vigentes, adolece de los mismos defectos. Solo abandonando la condicionalidad pueden superarse

Por ello la renta básica universal aparece como una solución que supera casi todos esos problemas de forma mucho más eficiente. Frente a las condiciones, una renta incondicionada; frente al proceso de solicitud y aprobación previa, una renta automática; frente a los retrasos, una renta previa a la necesidad; frente a la burocracia, un programa de gestión mínima; frente a los costes para 
administración y administrados, mínimos despilfarros; frente a la trampa de la pobreza, una renta compatible con otros ingresos; frente al error de salto, un beneficio progresivo; frente a la estigmatización de la pobreza, una renta de ciudadanía.

Todos los grandes avances sociales de la historia han necesitado un largo periodo de maduración y lucha, bajo el fuego granizado del anuncio de las grandes catástrofes que conllevarían. La renta básica no se libra de esa maldición.

La crítica fundamental es que desincentivaría el empleo: pagaríamos a los vagos con cada vez menos personas dispuestas a trabajar. Ya los programas de rentas mínimas parecen demostrar el escaso fundamento de tal prejuicio: son programas con más dinamismo de lo que se teme. En cualquier caso, podemos prever que ese hipotético efecto será siempre menor que en los programas habituales de rentas condicionadas: al ser compatible con ingresos de trabajo, reduce el efecto "trampa de la pobreza".

Las experiencias disponibles se han extendido por todo el mundo y todo tipo de países, con resultados abrumadoramente positivos. Admitiendo la precaución de que se trata de experimentos, con las evidentes limitaciones que ello implica, coinciden en que no hay efectos significativos sobre búsqueda de empleo y sí un leve aumento del emprendimiento. Cuando se observa alguna leve reducción de tiempo de trabajo, lo es en empleos remunerados, pero con aumento del tiempo dedicado a otros empleos como cuidados, voluntariado o aficiones artísticas. Lo que nos llevaría a otro debate importante: qué entendemos por trabajo socialmente útil y cómo medimos el bienestar.

Una constante en las conclusiones de los experimentos realizados es que se observa, amén del descenso de índices de pobreza, mejoras en salud mental y disminución de depresiones en los participantes, un menor estrés y la reducción de visitas a médicos y hospitales, así como el descenso en absentismo y abandono escolar y en índices de delincuencia.

Resulta especialmente llamativo el reciente experimento finlandés, que algunos presentaron como un fracaso porque "no ha servido para impulsar el empleo entre sus beneficiarios”. ¡Recordemos que el pronóstico descalificante es que caerá! Nadie puede presentar la renta básica como impulsora de empleos. Aunque algunos se empeñen en culpar a los parados, dependerá más de la situación del mercado de trabajo que de la voluntad de cada trabajador.

Los resultados finales señalan que la renta básica dio lugar a un pequeño aumento del empleo. Es decir, que lejos de estimular la vagancia, se observa un leve efecto positivo. Es decir, que lejos de estimular la vagancia, se observa un leve efecto positivo, casi neutral.

Pero, además, se dijo al presentar los primeros datos: "Los beneficiarios de la prestación mostraron una percepción claramente mejor de su bienestar en comparación con el grupo de control, refiriendo menos problemas de estrés y de salud, así como expresando una mayor confianza respecto de su futuro y oportunidades”. ¿ No es esto en sí mismo un enorme efecto positivo, suficiente para defender la renta básica?

Otro argumento habitual es que no puede aceptarse una prestación a cambio de nada, ni que se reconozca a los ricos el mismo derecho que a los pobres. Es un argumento falso porque los derechos básicos están asegurados por la mera condición de ciudadanía. ¿Acaso la educación y la sanidad pública se reconocen solo a los pobres o a cambio de algo? ¿No incluye nuestro IRPF un mínimo personal y familiar a todos los contribuyentes?

Es un argumento falso también porque no es a cambio de nada: esas prestaciones se reciben a cambio de nuestros impuestos. El pago de tributos es la garantía de nuestros derechos. La renta básica aparece, así, como un seguro que el Estado reconoce a toda la ciudadanía: usted pague sus impuestos y a cambio, entre todos sus derechos, le garantizamos que recibirá una renta mínima que le ayude a vivir con dignidad cuando lo necesite. La mejor forma de hacerlo es reconocerlo a priori, de forma que si le sobreviene la necesidad por sorpresa el colchón esté colocado de antemano para amortiguar su caída. 
Tras el debate del IMV sabemos que una renta mínima garantizada es un derecho sin marcha atrás. Su aplicación y la experiencia nos han mostrado que su funcionamiento (como el de cualquier renta condicionada) es deficiente. Parece evidente que hay que dar el salto a la renta básica y que lo que procede ahora ya es el debate del cómo, para que el cuándo sea lo antes posible.

Ya sabemos que no es más que un parche, que no soluciona la mayoría de los problemas, que no hay que abandonar el objetivo del pleno empleo, que es mejor solucionar las causas y no las consecuencias de la pobreza y la desigualdad. Pero mientras se consiguen tan ambiciosos objetivos hay que dar respuesta urgente y eficaz a las personas en riesgo de exclusión social.

Ya sabemos que no hay experiencia. Todos los avances tienen una primera vez y pocos hay que dispongan de tantos y tan variadas pruebas previas, todas positivas.

Ya sabemos que hay quienes quieren presentarla como carísima e imposible de financiar. Pero eso no es cierto. Aceptemos la cuantía individual del IMV como punto de partida. Solo con las prestaciones existentes que resultan absorbidas y el propio aumento de recaudación que podría generarse por incrementos en el consumo, tendríamos recursos para una renta básica que llegara a casi el 50\% de los hogares. Basta, por tanto, con recuperar de forma progresiva (evitemos el error de salto) ese 50\% a través de retenciones adaptadas en el IRPF. Los hogares de las primeras decilas no devolverían nada (recibirían neto el 100\%). Las retenciones progresivamente crecientes dejarían una renta básica decreciente según el nivel de renta y permitirían reducir el coste hasta la cuantía deseable. Sin perjuicio de la necesaria reforma fiscal que busque una financiación global más justa de nuestros servicios públicos.

Tenemos que llegar a soluciones sobre aspectos manifiestamente mejorables del IMV, que la premura de su implantación no ha posibilitado. Entre ellos, sin duda, la coordinación con Comunidades Autónomas y las rentas mínimas preexistentes. Y la posible cooperación de ayuntamientos y organizaciones del Tercer Sector. O mejorar el tratamiento de los jóvenes, concibiendo la renta básica como una renta de emancipación, por ejemplo.

Estos debates no son fáciles porque están cargados de apriorismos. En ambos extremos del espectro ideológico hay quienes se cierran en banda a cualquier posibilidad para la implantación de la renta básica. Para unos es una propuesta comunista, para otros ultraliberal. Ni una cosa ni la otra. Pero, aunque así fuera, ¿seremos capaces de admitir que hasta nuestros contrarios pueden tener de vez en cuando alguna idea aceptable? Utilicemos argumentos, no adjetivos descalificadores, y avancemos rápidamente hacia una medida que ya resulta imparable. Sin perjuicio de otros muchos debates paralelos (justicia fiscal, pensiones, mercado de trabajo, ...) que son igualmente necesarios.

\section{Referencias}

AIREF (2019): LOS PROGRAMAS DE RENTAS MÍNIMAS EN ESPAÑA. https://www.airef. es/wp-content/uploads/RENTA_MINIMA/20190626-ESTUDIO-Rentas-minimas.pdf

BOLLAIN, J. Y RAVENTÓS, D. (2019): "La Renta Básica Incondicional ante las limitaciones de las Rentas Mínimas". SIN PERMISO. 04/01/2019.

COMISIÓN EUROPA (2019): The Impact of the Digital Transformation on EU Labour Markets. Report of the high-level expert group. European Commission. Brussels

NOGUERA J.A. European Social Survey (2016). EL PAÍS: 9/02/2019.

GIMENO ULLASTRES, J.A. (2015): Aproximación a una renta básica sostenible. En Ayala, L. y Ruiz Huerta, J. (eds.): Segundo informe sobre la desigualdad en España. Fundación Alternativas, Madrid, págs. 97-103.

- (2019): “De rentas mínimas a renta básica”. Revista Diecisiete. Octubre, págs.59-80. 
- (2019): "Modelos de financiación de una renta básica para España”, con Díaz Oyarzábal y Gómez Frías. Revista Diecisiete. Octubre, págs.135-160.

- (2019): "Un Estado de bienestar más redistributivo". En Ayala, Martínez y Loscos (coords.): "El futuro del Sector Público". Estudios de Hacienda Pública Instituto de Estudios Fiscales. Madrid.

LLANO ORTIZ, J. C. (2018): El estado de la pobreza: seguimiento del indicador de pobreza y exclusión social en España 2008-2017. (Informe AROPE). EAPN - ES. https://www.eapn.es/ estadodepobreza/ARCHIVO/documentos/Informe_AROPE_2018.pdf

- (2020): El paisaje del abandono: La pobreza severa en España. EAPN - ES. https://www.eapn. es/ARCHIVO/documentos/noticias/1594898863_el-paisaje-del-abandono.-la-pobreza-severa-en-espana-correccion 16072020.pdf

MALGESINI, G. (2020): The impact of COVID-19 on people experiencing poverty and vulnerabity. EAPN Report. https://www.eapn.eu/wp-content/uploads/2020/07/EAPN-EAPN_REPORT_IMPACT_COVID19-4554.pdf

MARTÍNCARRETERO, J.M. (2019): Nueva desigualdad en España y nuevas políticas para afrontarla. En Sevilla, J. (Coord.): Reforzar el bienestar social: del ingreso mínimo a la renta básica, p. 17. Observatorio Social de la Caixa. https:/observatoriosociallacaixa.org/documents/22890/182418/ Informe+renta+basica_es.pdf/3642780f-87f5-8141-5993-864af1851e31

NACIONES UNIDAS (2020). Informe del Relator Especial sobre la extrema pobreza y los derechos humanos (Visita a España). A/HRC/44/40/Add.2. https://undocs.org/es/A/HRC/44/40/Add.2

OXFAM-INTERMON (2020): Una reconstrucción justa y necesaria es posible'. https://cdn2. hubspot.net/hubfs/426027/Oxfam-Website/oi-informes/informe-pobreza-desigualdad-pandemia-covid-19.pdf 